\title{
REGIONAL SHEAR STRESS OF BROKEN FOREST FROM RADIOSONDE WIND PROFILES IN THE \\ UNSTABLE SURFACE LAYER
}

\author{
MARC B. PARLANGE
}

Hydrologic Science, Department of Land, Air and Water Resources and Department of Agricultural Engineering, Veihmeyer Hall, University of California, Davis, CA 95616, U.S.A.

and

\section{WILFRIED BRUTSAERT}

School of Civil and Environmental Engineering, Hollister Hall, Comell University, Ithaca, NY 14853, U.S.A.

(Received in final form 10 August, 1992)

\begin{abstract}
Mean wind speed profiles were measured by tracking radiosondes in the unstable atmospheric boundary layer $(\mathrm{ABL})$ over the forested Landes region in southwestern France. New Monin-Obukhov stability correction functions, recently proposed following an analysis by Kader and Yaglom, as well as the Businger-Dyer stability formulation were tested, with wind speeds in the surface sublayer to calculate the regional shear stress. These profile-derived shear stresses were compared with eddy correlation measurements gathered above a mature forest stand at a location roughly $4.5 \mathrm{~km}$ from the radiosonde launch site. The shear stress values obtained by means of the newly proposed stability function were in slightly better agreement with the eddy correlation values than those obtained by means of a Businger-Dyer type stability function. The general robustness of the profile method can be attributed in part to prior knowledge of the regional surface roughness $\left(z_{0}=1.2 \mathrm{~m}\right)$ and the momentum displacement height $\left(d_{0}=6.0 \mathrm{~m}\right)$, which were determined from neutral wind profile analysis. The $100 \mathrm{~m}$ drag coefficient for the unstable conditions above this broken forest surface was found to be $u_{*}^{2} / V_{100}^{2}$ $=0.0173$.
\end{abstract}

\section{Introduction}

The surface shear stress $\tau_{0}$, usually expressed as a velocity scale, called the friction velocity $u_{*}\left[\equiv\left(\tau_{0} / \rho\right)^{1 / 2}\right]$, is one of the essential variables in Monin-Obukhov similarity theory to describe turbulence in the surface sublayer or inner region of the atmospheric boundary layer (ABL). It is ubiquitous in all flux-profile relationships, but it appears probably most naturally in the wind speed gradient

$$
\frac{\mathrm{d} V}{\mathrm{~d} z}=\frac{u_{*}}{k\left(z-d_{0}\right)} \varphi_{m}(y)
$$

where $V$ is the wind speed, $z$ the height above the ground, $k$ von Karman's constant herein taken as 0.4 , and $d_{0}$ the (zero-plane) displacement height; $\varphi_{m}=$ $\varphi_{m}(y)$ is the Monin-Obukhov stability function, in which $y=\left[\left(z-d_{0}\right) / L\right]$ and

$$
L=\frac{-u_{*}^{3}}{k g\left[H_{v} / \rho c T_{a}\right]}
$$

Boundary-Layer Meteorology 64: 355-368, 1993.

(C) 1993 Kluwer Academic Publishers. Printed in the Netherlands. 
is the Obukhov length; $H_{v}=\left(H+0.61 T_{a} c_{p} E\right)$ is the specific flux of virtual sensible heat at the surface, $H$ the specific flux of sensible heat, $E$ the evaporation rate, $g$ the acceleration of gravity, $\rho$ the density of the air, $c_{p}$ the specific heat at constant pressure and $T_{a}$ the air temperature near the ground. For unstable conditions, which are of interest here, the stability function $\varphi_{m}$ has been the subject of numerous experimental studies. Until a few years ago, the consensus based on the field observations was that the Businger-Dyer formulation (e.g., Dyer, 1974; Businger, 1988; Högström, 1988), viz., in a general form

$$
\varphi_{m}=(1-C y)^{-1 / 4}
$$

where $C$ is a constant, gives a good description of the available data. However, almost all of the field studies on which (3) was based produced data for $(-y)$ smaller than 2.0; thus little was known about the behavior of $\varphi_{m}$ for large values of $(-y)$, which represent strongly unstable conditions or measurements at higher elevations in the surface layer. More recently, following a theoretical analysis by Kader and Yaglom (1990) with a data collection with values of $(-y)$ up to 20 , Brutsaert (1992) suggested as an interpolation function

$$
\varphi_{m}=\left[\left(a+b x^{n}\right) /\left(a+x^{n}\right)\right]+c x^{1 / 3}
$$

where $x=-y$, and $a, b, c$ and $n$ are constants, to be specified below.

In practical applications, the wind speed profile, which is the integral of (1), is often written in the form

$$
V=\frac{u_{*}}{k}\left[\ln \left(\frac{z-d_{0}}{z_{0}}\right)-\Psi_{m}(y)\right]
$$

in which $z_{0}$ is the roughness length and $\Psi_{m}$ is the stability correction function, defined by

$$
\Psi_{m}(y)=\int_{z 0^{\prime} / L}^{y}\left[1-\varphi_{m}(z)\right] \mathrm{d} z / z
$$

This can be readily integrated using the two $\varphi_{m}$-functions. Thus the correction function derived from the Businger-Dyer formulation (3) is

$$
\Psi_{m}(y)=\ln \left[\frac{(1+u)^{2}\left(1+u^{2}\right)}{\left(1+u_{0}\right)^{2}\left(1+u_{0}^{2}\right)}\right]-2 \arctan (u)+2 \arctan \left(u_{0}\right)
$$

where $u=(1-C y)^{1 / 4}$ and $u_{0}=\left(1-C z_{0} / L\right)^{1 / 4}$; in this paper the value $C=16$ is used, which is typical for $k=0.4$. In the integration of (6) with (4), two sets of constants were used. In the first implementation, the constants in (4) were chosen to produce a close fit with the data of Kader and Yaglom (1990). The result was (Brutsaert, 1992) the following (for $k=0.4$ ) 


$$
\begin{aligned}
\Psi_{m}(y)= & 0 \text { for } y>-0.0093 \\
\Psi_{m}(y)= & 1.72 \ln \left[\frac{\left(0.37+x^{0.72}\right)}{0.37+\left(0.0093+x_{0}\right)^{0.72}}\right] \\
& -1.50\left[x^{1 / 3}-\left(0.0093+x_{0}\right)^{1 / 3}\right] \text { for } y \leqslant-0.0093
\end{aligned}
$$

where, again, $x=-y$ and $x_{0}=-z_{0} / L$. In the second implementation of (4), the constants were selected as a compromise between the data set of Kader and Yaglom (1990) and the several earlier data sets for small $(-y)$, as exemplified by Högström (see Brutsaert, 1992). The proposed form was

$$
\begin{aligned}
\Psi_{m}(y)= & 0 \text { for } y>-0.00059 \\
\Psi_{m}(y)= & 1.47 \ln \left[\frac{\left(0.28+x^{0.75}\right)}{0.28+\left(0.0059+x_{0}\right)^{0.75}}\right] \\
& -1.29\left[x^{1 / 3}-\left(0.0059+x_{0}\right)^{1 / 3}\right] \text { for }-0.0059 \geqslant y \geqslant-15.025 \\
\Psi_{m}(y)= & \Psi_{m}(-15.025) \text { for } y<-15.025
\end{aligned}
$$

As an illustration, the three forms of $\Psi_{i n}$, namely (7), (8), and (9) $\left(y_{0}=0\right)$, are plotted for $z_{0}=0$ in Figure 1 .

The surface-layer similarity scheme (1) has been developed and tested primarily for relatively smooth and homogeneous terrain; moreover, most experiments on which (3) and (4) are based, were conducted at the field scale with measurements at a few meters above the ground and effective fetches of the order of a few hundred meters, at most. Very few studies have dealt with rough surfaces such as forest or hilly terrain at more regional scales. Thom et al. (1975) were among the first to point out the difficulties encountered in the application of standard fluxprofile relationships above forests. Many subsequent studies (e.g., Garratt, 1978, 1979, 1980; Raupach, 1979; Denmead and Bradley, 1985; Cellier, 1986; Chen and Schwerdtfeger, 1989) have confirmed that profiles measured near a forest canopy are not well described by the standard surface-layer similarity functions.

In this paper, an analysis is presented of wind speed profiles measured with radiosondes under unstable atmospheric conditions over the Landes Forest in southwestern France, as part of the 1986 HAPEX-MOBILHY field campaign. The present study is a sequel to two earlier analyses (Parlange and Brutsaert; 1989, 1990) of wind profiles under neutral conditions during the same experiment. The main objective of the present paper is to explore the usefulness of the MoninObukhov similarity formulation with the measured profiles in order to estimate the friction velocity $u_{*}$ at the regional scale. The function (7), as well as (8) and (9), are considered in the process. The quality of the $u_{*}$ estimates from the wind speed profiles is assessed by comparing them with independent eddy correlation measurements of the shear stress made above the forest. 


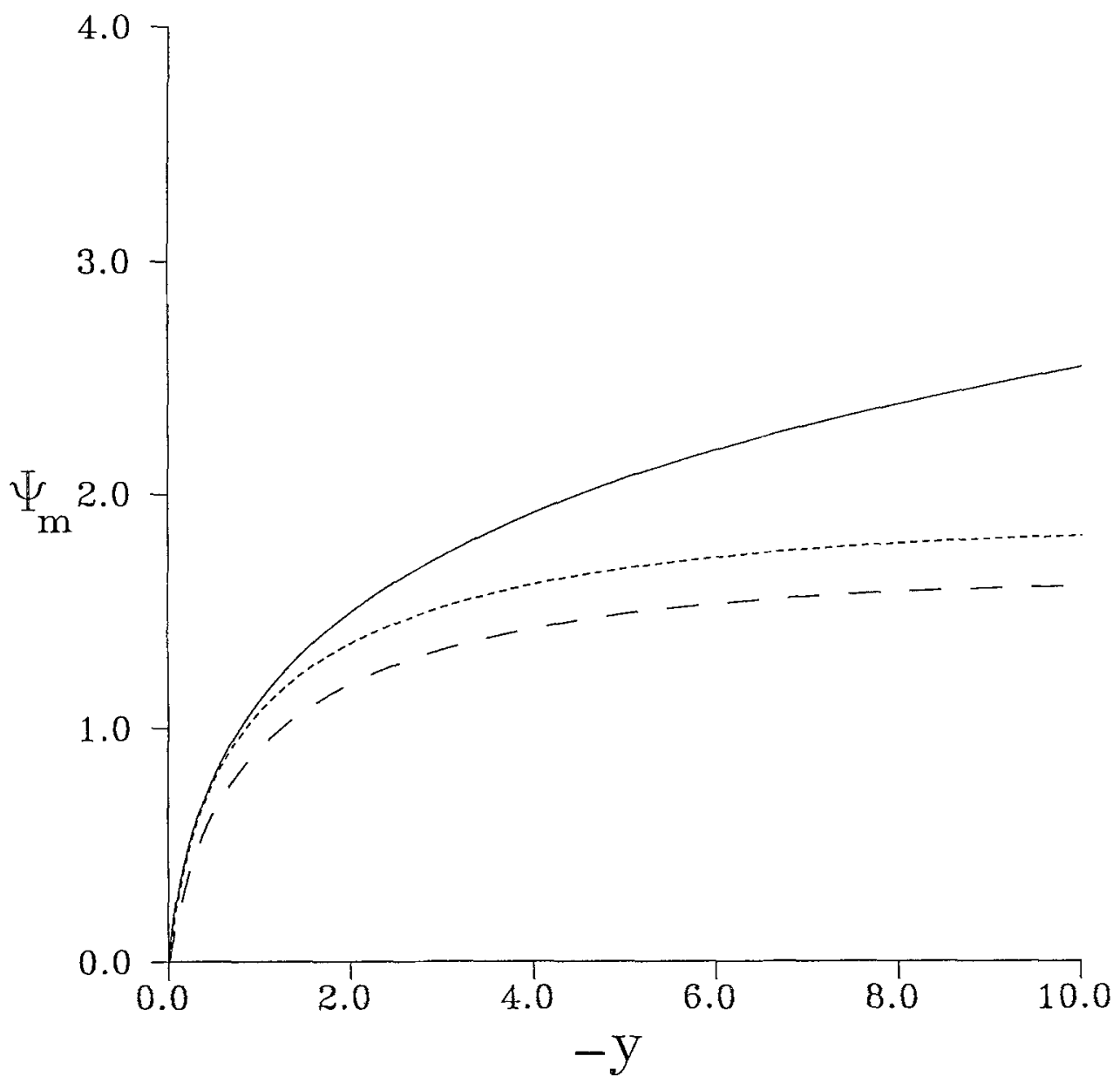

Fig. 1. The momentum stability correction functions $\Psi_{m}\left(z_{0}=0\right)$; (7), solid line; (8), long dashed line; (9), fine dashed line.

\section{Experiment}

The radiosonde wind speed profiles were collected during the HAPEX-MOBILHY (Hydrologic Atmospheric Pilot Experiment-Modelisation du Bilan Hydrique). The scope and general objectives of this experiment have been described by André et al. $(1986,1988)$. The launch site was situated near Lubbon $\left(00^{\circ} 03^{\prime} \mathrm{W}, 44^{\circ} 08^{\prime} \mathrm{N}\right)$ within the predominantly flat Landes Forest region. Approximately $65 \%$ of the area surrounding the launch site, within a radius of 5 to $10 \mathrm{~km}$, is covered by pine forest; the remaining land cover consists of agricultural clearings, remnants of logging operations and a few small villages. Further information on the experimental area and the radiosounding system have been presented by Parlange and Brutsaert $(1989 ; 1990)$ and Brutsaert et al. (1989). 
From May 6 through July 14, 1986, some 405 soundings were made. The time interval sampled for the mean velocity profile was taken as $10 \mathrm{~s}$, which corresponded to a vertical resolution of approximately $50 \mathrm{~m}$. The velocity profiles were derived by automatic radar tracking of the radiosonde position. From among the available soundings for the present analysis 62 unstable ones were selected on the basis of two additional criteria: (1) All three variables of the radiosounding (wind velocity, temperature and specific humidity) were measured; (2) eddy correlation measurements of shear stress, and of the sensible and latent heat fluxes are available at the time of the radiosonde flight. It was assumed that the surface was statistically uniform in all directions, and the profiles were not discriminated according to wind direction. The ABL was fairly well developed for all the profiles studied; the height of the capping inversion $h_{i}$ for all soundings was more than $300 \mathrm{~m}$ above the ground.

The eddy correlation shear stress measurements were used to assess the quality of $u_{*}$ estimates from the wind speed profiles. The eddy correlation measurements of the fluxes $H$ and $E$ were needed to determine the Obukhov length by means of (2). The eddy correlation flux station was located atop a mast above $29 \mathrm{~m}$ above the ground and about $9 \mathrm{~m}$ above the tree tops, in an area of mature forest, some $4.5 \mathrm{~km}$ southwest of the release site. This flux station was operated by a research team from the Institute of Hydrology, Wallingford, Great Britain. The system measured hourly flux averages (see Shuttleworth et al., 1984; 1988; Gash et al., 1989); for the present study, these were interpolated to the release times of the sondes. The earlier studies (Parlange and Brutsaert, 1989; 1990; Brutsaert et al., 1989) of the neutral wind speed and humidity profiles have already provided a strong indication that the flux measurements made at the mast represent good estimates at the regional scale.

\section{Wind Speed Profile Analysis}

\subsection{THE SURFACE SUBLAYER}

In order to apply (1) or (5), it is necessary to know the height range of the surface sublayer. In the analysis of the neutral wind speed profiles (Parlange and Brutsaert, 1989) the mean range of this inner region was found to be $86 \pm 22 \mathrm{~m} \leqslant z \leqslant 160 \pm 38 \mathrm{~m}$. It was noted in the study of neutral wind profiles that once the typical inner region range was known and $z_{0}$ and $d_{0}$ had been established, the omission or addition of a rawinsonde wind speed measurement at the upper or lower end of this range did not change the estimate of shear stress appreciably. This was an important result since a reliable estimate of the regional shear stress could be obtained from the wind profile once the zero velocity intercept was set and some average range of the inner region of the $A B L$ was specified.

In the present study, an analysis of the unstable wind profiles was first carried out to establish "optimal" height ranges for application of (5) using the stability 
correction functions given by (7)-(9). For each individual profile, the optimal range of wind speed measurements above the land surface may be defined as the range for which the profile-derived $u_{*}$ matches best the eddy correlation value. The objective was to check if the different stability correction formulations (7)(9) in the Monin-Obukhov similarity model result in optimal ranges which differ from one another and from the range obtained earlier in the neutral wind study. The Obukhov length was calculated from the eddy correlation measurements taken at the Institute of Hydrology mast and for each wind profile the range was selected such that the $u_{*}$ obtained with (5) was closest to the surface measurement. With the parameters $z_{0}=1.2 \mathrm{~m}$ and $d_{0}=6.0 \mathrm{~m}$, known from the analyses of the neutral profiles, the mean height ranges ( \pm standard deviations) for all 62 profiles analyzed were found to be:

$$
\begin{aligned}
& 89( \pm 41) \mathrm{m} \leqslant z \leqslant 183( \pm 50) \mathrm{m} \text { for }(7) \\
& 84( \pm 39) \mathrm{m} \leqslant z \leqslant 177( \pm 46) \mathrm{m} \text { for }(8) \\
& 76( \pm 38) \mathrm{m} \leqslant z \leqslant 181( \pm 39) \mathrm{m} \text { for }(9) .
\end{aligned}
$$

These results show that the extent of the unstable surface sublayer as determined by the fit of (5) to obtain the best $u_{*}$ value for each individual profile does not depend strongly on the stability correction function used; indeed, the mean limits cannot be considered different at the 0.05 level of significance. The average lower surface sublayer limit is comparable with the average neutral profile lower limit $(86 \mathrm{~m})$ though the standard deviation of the limits found above are about twice the standard deviation of the neutral range lower limit. The average upper limit extends some $20 \mathrm{~m}$ above the neutral range. In general, the neutral profile analysis appears to give a reasonable estimate of the surface-layer range under unstable conditions which is useful for applications at other sites over heterogeneous terrain. The ranges are also very similar to those obtained for the temperature and humidity profiles of the same unstable soundings (see Brutsaert and Parlange, 1992). The overall regression comparison of the "optimal" $u_{*}$ 's found above, obtained by matching the closest profile-derived flux against the friction velocities measured with the eddy correlation system, is presented in Table I. The slope of the regression lines forced through the origin are not different from unity at the $95 \%$ confidence level and the coefficients of determination $\left(R^{2}\right)$ are about 0.90 for all three stability functions tested.

When the surface parameters $\left(z_{0}\right.$ and $\left.d_{0}\right)$ and the average ABL surface sublayer range are known for a given region, the question is: how robust is the MoninObukhov similarity analysis for the determination of $u_{*}$, with the different stability correction functions, if the wind speed measurements between some prespecified limits are used? This is addressed below in a wind profile analysis where the mean inner region height ranges obtained from the neutral analysis $(86 \mathrm{~m} \leqslant z \leqslant 160 \mathrm{~m})$ (Parlange and Brutsaert, 1989) and from the unstable analysis ( $80 \mathrm{~m} \leqslant z \leqslant 180 \mathrm{~m}$ ) are used. An additional check on the robustness of the profile analysis was carried 


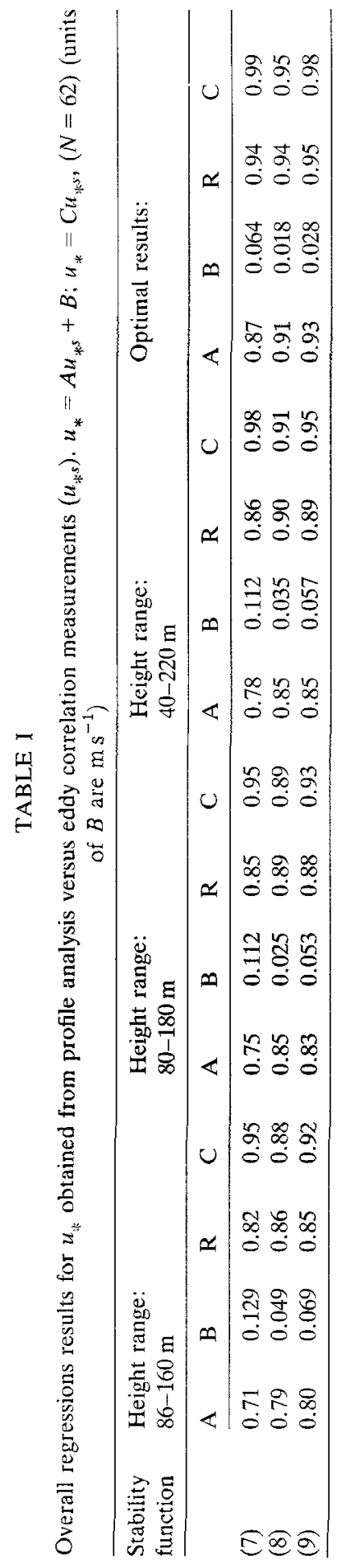


out using the wind speed measurements between 40 and $220 \mathrm{~m}$. These limits represent the average optimal unstable range extended out one standard deviation $(40 \mathrm{~m})$ at the lower and upper limits.

\subsection{Application of FLUX-PROFILE FunCtions}

For each wind speed profile, (5) was fitted to all the measured wind speed values measured in the height ranges $(86-160 \mathrm{~m}),(80-180 \mathrm{~m})$ and $(40-220 \mathrm{~m})$. The wind speed profile analysis was done by linear regression of $\ln \left[\left(z-d_{0}\right) /\right.$ $\left.\exp \left(\Psi_{m}(y)\right)\right]-\ln \left(z_{0}\right)$ versus $V$, through the origin. The Obukhov length in $y$ was calculated from the eddy flux measurements above the forest and each of (7), (8) and (9) was used to calculate the stability correction function $\Psi_{m}(y)$.

The overall regression analysis of the profile-derived friction velocities versus the eddy correlation measurements is presented in Table I. None of the correlation coefficients are significantly different at the 0.05 level of significance regardless of what stability function or inner layer region is used. In general, the correlation coefficient increases as a larger interval is used to define the surface sublayer. The slope of the regression line forced through the origin is not different from unity at the 0.05 level for all stability correction functions used and ranges tested. However, use of (8) appears on average to underpredict the measured friction velocities. That all the regression slopes approach unity when a larger range is used, is attributed in part to the somewhat coarse vertical resolution of the rawinsonde profiles. The inclusion of more wind speed measurements allows for a better realization of the mean wind speed profile in the ABL surface sublayer. That the statistical results do no differ significantly for the different ranges tested, for each of (7), (8) and (9), demonstrates that the profile analysis is robust with respect to the inner range selected. This finding is similar to what was observed in the neutral wind speed profile analysis (see Parlange and Brutsaert, 1989).

The $u_{*}$ values derived by the procedure with $\Psi_{m}$ functions (7), (8) and (9) are compared in Figures 2, 3 and 4, respectively, with the eddy correlation measurements denoted by $u_{* s}$ with measurements made between 80 and $180 \mathrm{~m}$ above the land surface. The correlation coefficients for $u_{*}$ versus $u_{* s}$ are $0.85,0.89$ and 0.88 and the slopes of the regression line set through the origin are $0.95,0.89$ and 0.93 , for functions (7), (8) and (9), respectively. The results shown in Table I demonstrate that on average there is no clear difference in the values of $u_{*}$ obtained using either (7) or either of (8) or (9). None of the slopes forced through the origin are significantly different from unity at the $95 \%$ confidence level.

To test if there is any change in the results using the new stability correction functions, all the wind speed profiles were separated into two groups based on whether $-180 / L$ was greater or smaller than $3 ; z=180 \mathrm{~m}$ corresponds to the optimal mean upper limit of the ABL surface sublayer range. For the 62 profiles analyzed, 30 releases occurred when $-180 / L$ was smaller than 3 and the remaining 32 releases took place when $-180 / L$ was greater than 3 . This demonstrates that in the calculation of regional-scale surface fluxes with measurements at around 


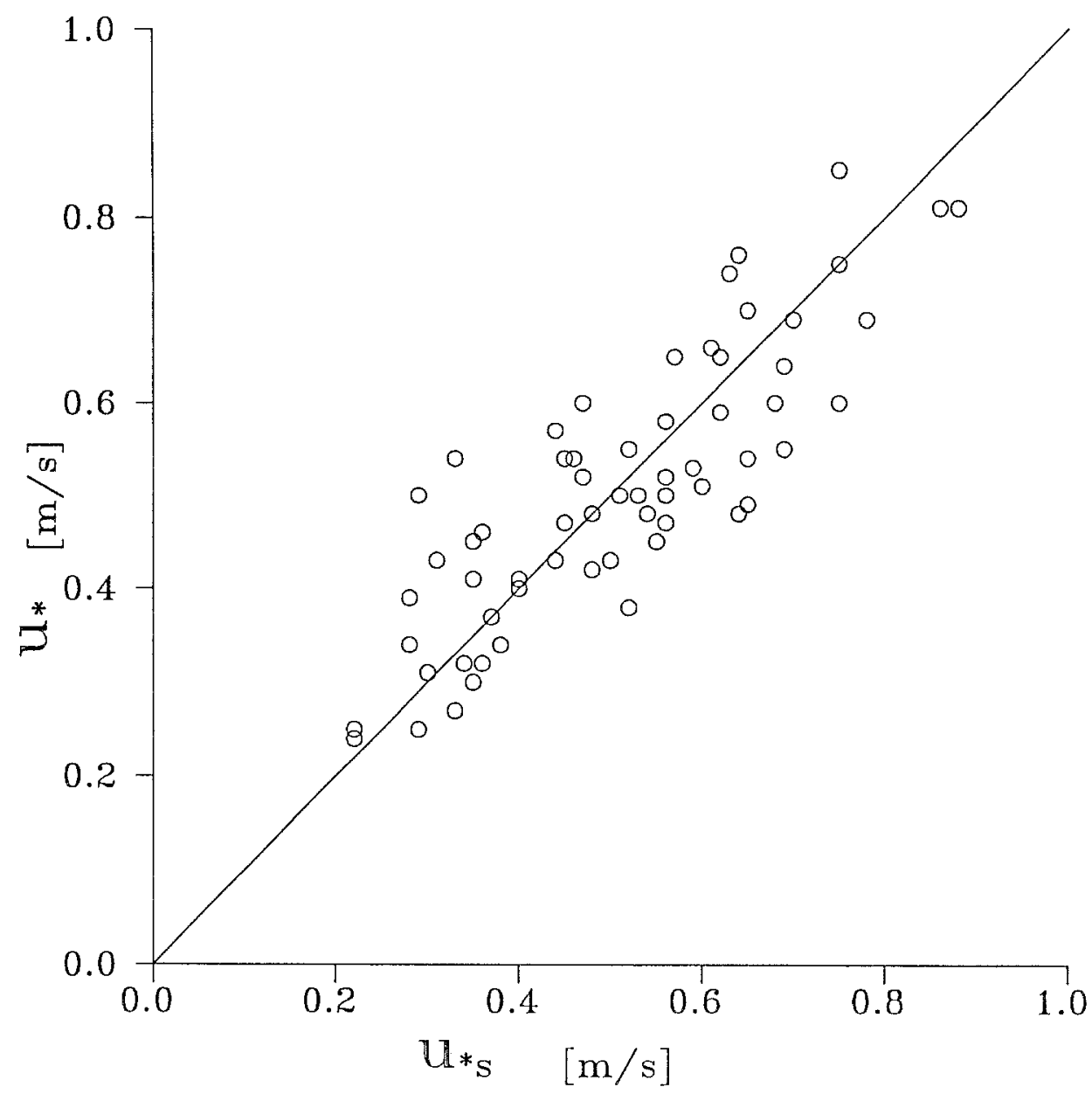

Fig. 2. Comparison between the $u_{*}$ values derived from wind profiles $(80-180 \mathrm{~m})$ analyzed in the context of Monin-Obukhov similarity with the BD stability correction function (7), and the $u_{* s}$ values measured some $4.5 \mathrm{~km}$ away by means of the eddy correlation method $9 \mathrm{~m}$ above the tree tops. The correlation coefficient is $R=0.85$.

100 to $200 \mathrm{~m}$, large values of $(-y)$ are not unusual and it is important to know the stability correction function for such values of $y$. The regression analysis presented above for all 62 profiles was repeated for the two groups of 30 and 32 profiles. The regression results are presented in Table II. It can be seen that all the correlation coefficients are similar for the three different stability correction functions ( $95 \%$ level of significance). In addition, none of the slopes of the regression lines forced through the origin is significantly different from 1.0. Nevertheless, it is clear in the $u_{*}$ comparison for $-180 / L<3$ that the slopes through the origin using functions (7) or (9) are closer to 1.0 than the regression slope 


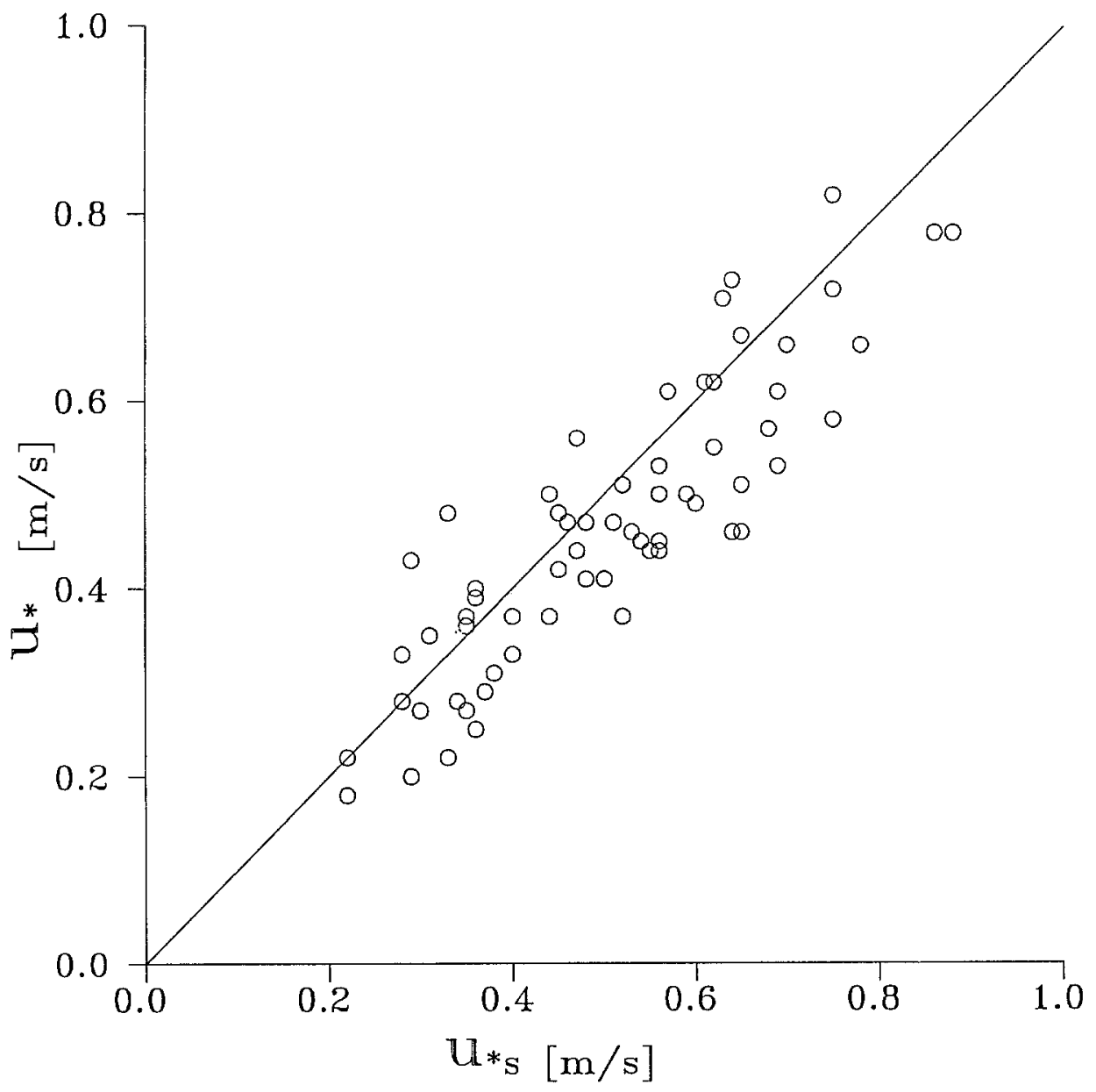

Fig. 3. Same as Figure 2 but with the stability correction function (8). The correlation coefficient is $R=0.89$.

\section{TABLE II}

Overall regression results for $-180 / L<3(N=30)$ and $-180 / L>3(N=32)$, using profile height range $80-180 \mathrm{~m}$ to calculate $u_{*} \cdot u_{*}=A u_{* s}+B ; u_{*}=C u_{* s}$ (units of $B$ are $\mathrm{m} \mathrm{s}^{-1}$ )

\begin{tabular}{lllllllll}
\hline Stabililty function & \multicolumn{2}{c}{$-180 / L<3$} & \multicolumn{7}{c}{$-180 / L>3$} \\
\cline { 2 - 9 } & $\mathrm{A}$ & $\mathrm{B}$ & $\mathrm{R}$ & $\mathrm{C}$ & $\mathrm{A}$ & $\mathrm{B}$ & $\mathrm{R}$ & $\mathrm{C}$ \\
\hline$(7)$ & 0.90 & 0.0074 & 0.74 & 0.91 & 0.90 & 0.064 & 0.77 & 1.06 \\
$(8)$ & 0.92 & -0.028 & 0.77 & 0.88 & 0.91 & 0.0047 & 0.79 & 0.92 \\
$(9)$ & 0.90 & 0.0054 & 0.74 & 0.91 & 0.95 & 0.015 & 0.79 & 0.99 \\
\hline
\end{tabular}




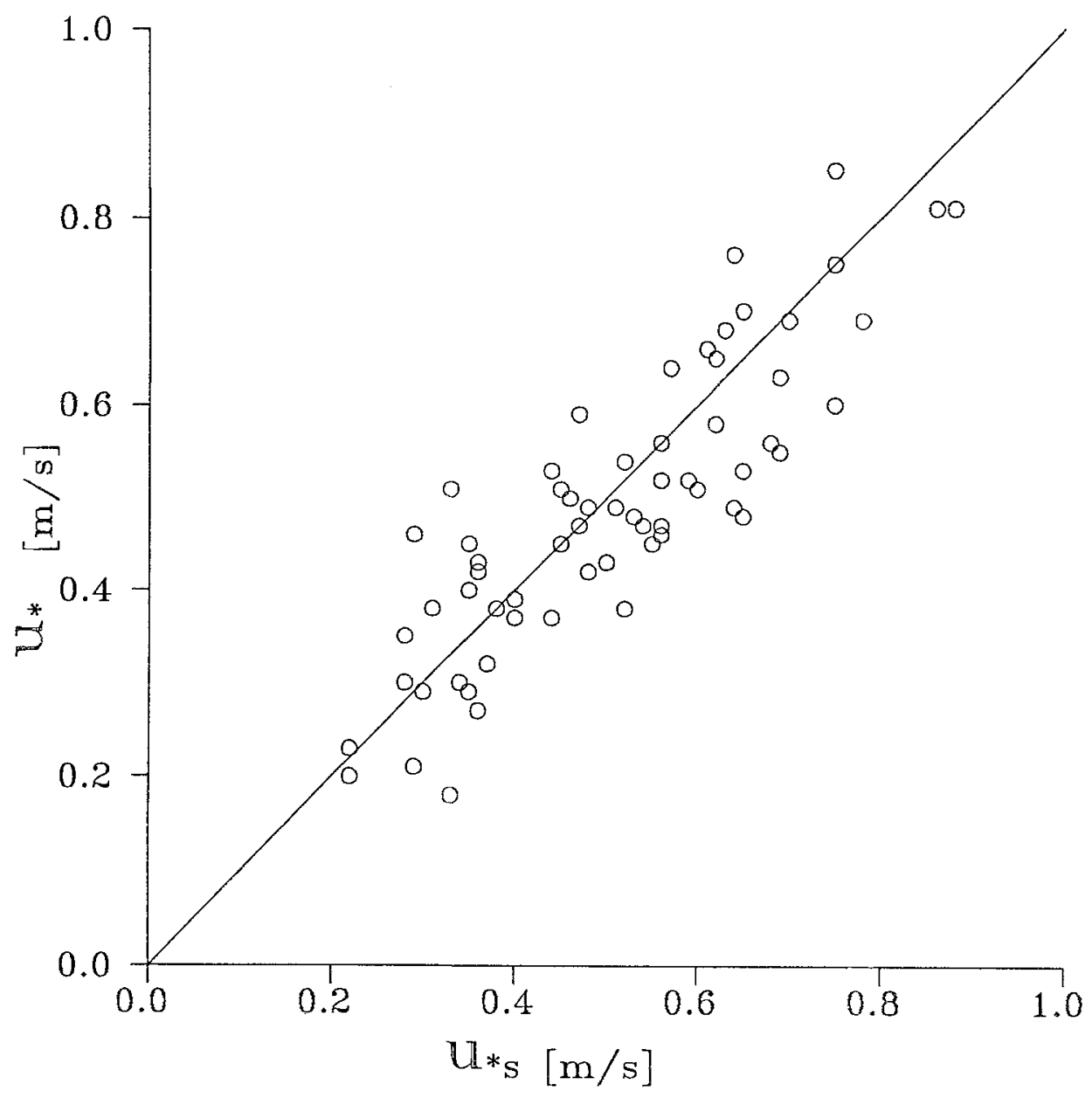

Fig. 4. Same as Figure 2 but with the stability correction function (9). The correlation coefficient is $R=0.88$.

using (8), which is based on the Kader-Yaglom data set. On the other hand, for $-180 / L>3$, the $u_{*}$ values obtained using (9) are closer to unity than those using (7) and (8). Hence, the present results show that on average, (9) represents a small but useful improvement, combining advantages of both (7) and (8) for situations where $y$ may vary over a broad range.

\subsection{Drag Coefficient $(100 \mathrm{~m})$}

In many applied situations, a useful stress estimate can be obtained by means of a simple drag coefficient. This is defined by

$$
C d_{r}=\frac{u_{*}^{2}}{V_{r}^{2}}
$$




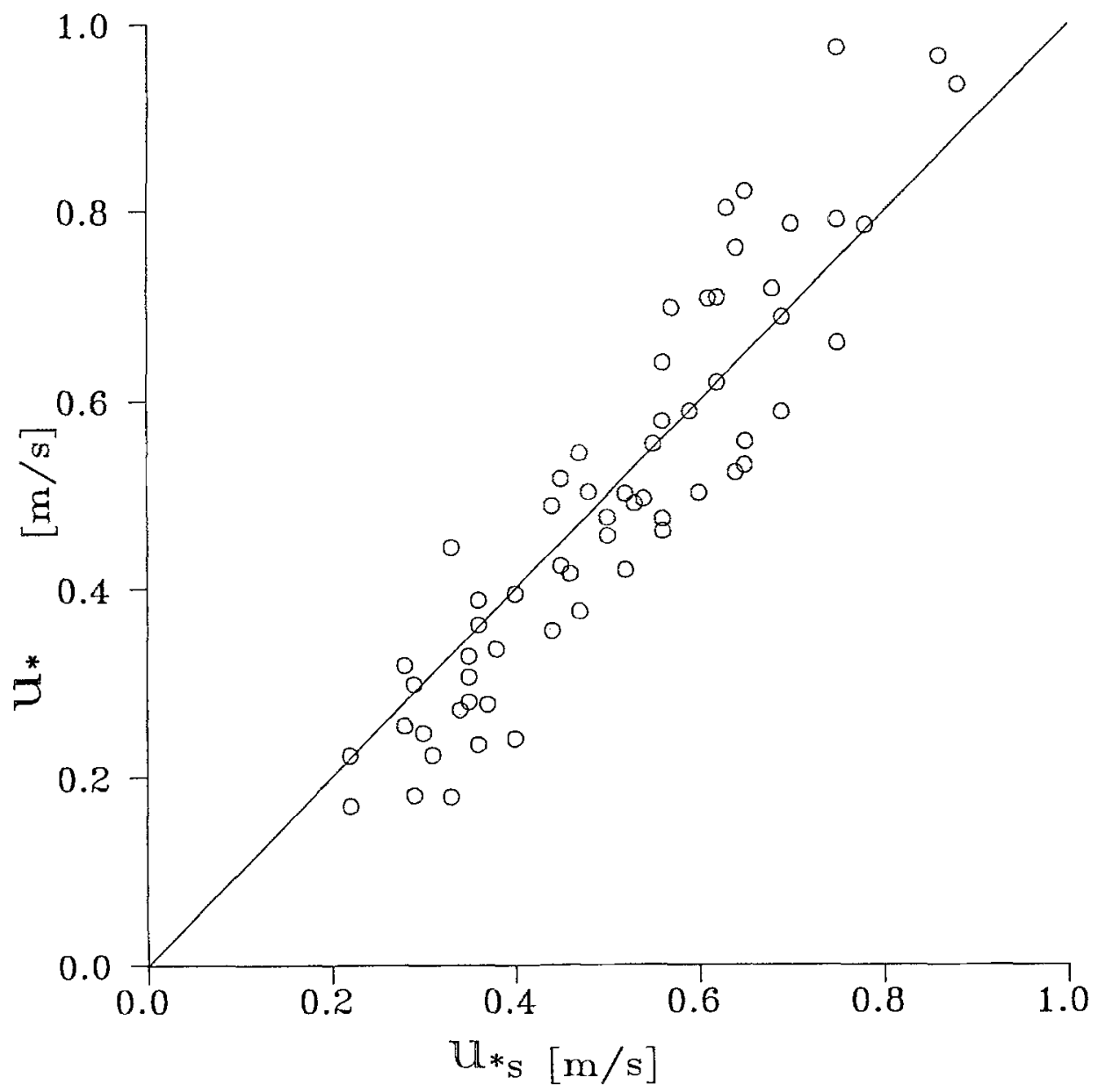

Fig. 5. Comparison between the $u_{*}$ values derived from the $100 \mathrm{~m}$ wind speed by means of the unstable drag coefficient $C d_{100}$ versus the $u_{* s}$ values. The correlation coefficient is $R=0.92$.

in which the subscript $r$ indicates the reference height $\left(z_{r}-d_{0}\right)$ at which $V_{r}$ is measured; for simplicity, this reference height was taken as $100 \mathrm{~m}$. To determine $C d_{100}$, for each profile the wind speed at $\left(z-d_{0}\right)=100 \mathrm{~m}$ was obtained from the regression by means of (5) with (9) through the wind profile measurements (80$180 \mathrm{~m}$ ) used in the analysis in Section 3.2. The value of $C d_{100}$ was determined by increasing $C d_{100}$ step-wise until the slope of the regression through the origin of $u_{* s}$ versus $u_{*}$ calculated with (11) became unity. The result of this exercise was $C d_{100}=0.0173$. The comparison plot of $u_{*}$ versus $u_{* s}$ from (11) is given in Figure 5 . The coefficient of correlation is $R=0.92$. The least-square linear regression that was obtained, $u_{*}=1.18 u_{* s}-0.1$, is comparable to the results obtained using (5) and any of (7), (8) or (9). 


\section{Conclusions}

The calculation of shear stress for complex or heterogeneous surfaces over length scales of tens of kilometers has particular significance for the linkage of land surface and atmospheric processes. Parameterizations of land-atmosphere interactions based upon surface-layer similarity typically require knowledge of the shear stress. This study of surface layer wind profiles measured with radiosondes demonstrates the value of Monin-Obukhov similarity analysis to obtain regional shear stress under unstable conditions. An advantage of Monin-Obukhov formulations, to describe wind speed measurements, is the general robustness of the approach. Once the inner-region range and the regional scale surface roughness (and displacement height) are established, all the wind profiles could be analyzed. All three stability correction functions tested produced about the same optimal ranges for the inner region, namely, $60 \leqslant\left(z-d_{0}\right) / z_{0} \leqslant 145$. The Monin-Obukhov model implemented with the stability function based in accordance with (9) agreed slightly better with eddy correlation measurements on average, than when implemented with (7) or (8). More experiments over different land surfaces need to be carried out to test the reliability of (9). The $100 \mathrm{~m}$ unstable drag coefficient over this forested region was $C d_{100}=0.0173$.

The measurements used in the analysis were taken at heights between 80 to $180 \mathrm{~m}$ above the ground. At those elevations, the atmospheric turbulence is the result of surface conditions over upwind distances of the order of $10^{4} \mathrm{~m}$ and perhaps more. Therefore, the surface shear stress values obtained in the analysis can be considered to be regional values at the same scale.

\section{Acknowledgements}

The authors are grateful to J. C. André and J. P. Goutorbe, of the CNRM of Toulouse, and to A. Perrier, of the INRA in Grignon, France, without whose inspiration and leadership the experiment for this study would not have been possible. They would also like to express their thanks to the members of the 4-M team of CNRM and others who were their helpful companions on the field crews. In addition, they would like to thank J. H. C. Gash, C. R. Lloyd and W. J, Shuttleworth of the Institute of Hydrology, Wallingford, Great Britain, who provided the eddy-correlation flux data.

This research has been supported and financed, in part, by the Division of Atmospheric Sciences of the National Science Foundation (ATM-8601115), by the National Aeronautics and Space Administration (NAG5-1378 and NAS5-31723), and by the University of California Water Resources Center.

\section{References}

André, J. C., Goutorbe, J. P. and Perrier, A.: 1986, 'HAPEX-MOBILHY: A Hydrologic Atmospheric 
Experiment for the Study of Water Budget and Evaporation Flux at the Climatic Scale', Bull. Am. Meteorol. Soc, 67, 138-144.

André, J. C., Perrier, A., Goutorbe, J. P. (and 28 co-authors): 1988, 'Evaporation over Land-Surfaces: First Results From HAPEX-MOBILHY Special Observing Period', Ann. Geophysicae 6, 477-492.

Brutsaert, W.: 1992, 'Stability Correction Functions for the Mean Wind Speed and Temperature in the Unstable Surface Layer, Geophysical Res. Letters 19(5), 469-472.

Brutsaert, W. and Parlange, M. B.: 1992, 'The Unstable Surface Layer Above Forest: Regional Evaporation and Heat Flux', Water Resources Research (in press).

Brutsaert, W., Parlange, M. B. and Gash, J. H. C.: 1989, 'Neutral Humidity Profiles in the Boundary Layer and Regional Evaporation for Sparse Pine Forest', Ann. Geophysicae 7, 623-630.

Businger, J. A.: 1988, 'A Note on the Businger-Dyer Profiles', Boundary-Layer Meteorol. 42, 145151.

Cellier, P.: 1986, 'On the Validity of Flux-gradient Relationships Above Very Rough Surfaces', Boundary-Layer Meteorol. 36, 417-419.

Chen, F. and Schwerdtfeger, P.: 1989, 'Flux-gradient Relationships for Momentum and Heat over a Rough Natural Surface', Quart. J. Roy. Meteorol. Soc. 115, 335-352.

Denmead, O. T. and Bradley, E. F.: 1985, 'Flux-gradient Relationships in a Forest Canopy', in B. A. Hutchison and B. B. Hicks (eds.), The Forest-Atmosphere Interaction, pp. 421-442, D. Reidel, Dordrecht.

Dyer, A. J.: 1974, A Review of Flux-Profile Relationships', Boundary-Layer Meteorol. 7, 363-372.

Garratt, J. R.: 1978, 'Flux-profile relations above Tall Vegetation', Quart. J. Roy. Meteorol. Soc. 104, 199-212.

Garratt, J. R.: 1979, "Comments on the Paper "Analysis of Flux-profile Relationships above Tall Vegetation - An Alternative View", Quart J. Roy Meteorol. Soc. 105, 1079-1082.

Garratt, J. R.: 1980, 'Surface Influence Upon Vertical Profiles in the Atmospheric Near-surface Layer', Quart. J. Roy. Meteorol. Soc. 106, 803-819.

Gash, J. H. C., Shuttleworth, W. J., Lloyd, C. R., André, J. C., Goutorbe, J. P. and Gelpe, J.: 1989, 'Micrometeorological Measurements in Les Landes Forest During HAPEX-MOBILHY', Agric. For. Meteorol. 46, 131-147.

Högström, U.: 1988, 'Non-dimensional Wind and Temperature Profiles in the Atmospheric Surface Layer: A Re-evaluation', Boundary-Layer Meteorol. 42, 55-78.

Kader, B. A. and Yaglom, A. M.: 1990, 'Mean Fields and Fluctuation Moments in Unstably Stratified Turbulent Boundary Layers', J, Fluid Mech. 212, 637-662.

Parlange, M. B. and Brutsaert, W.: 1989, 'Regional Roughness of the Landes Forest and Surface Shear Stress Under Neutral Conditions', Boundary-Layer Meteorol. 48, 69-81.

Parlange, M. B. and Brutsaert, W.: 1990, 'Are Radiosonde Time Scales Appropriate to Characterize Boundary Layer Wind Profiles?', J. Appl. Meteorol. 29, 249-255.

Raupach, M. R.: 1979, 'Anomalies in Flux-Gradient Relationships over Forest', Boundary-Layer Meteorol. 16, 467-486.

Shuttleworth, W. J., et al. (13 co-authors): 1984, 'Eddy Correlation Measurements of Eddy Partition for Amazonian Forest', Quant. J. Roy. Meteorol. Soc. 110, 1143-1162.

Shuttleworth, W. J., Gash, J. H. C., Lloyd, C. R., Moore, C. J. and Wallace, J. S.: 1988, 'An Integrated Micrometeorological System for Evaporation Measurement', Agric. For. Meteorol. 43, 295-317.

Thom, A. S., Stewart, J. B., Oliver, H. R. and Gash, J. H. C.: 1975, 'Comparison of Aerodynamic and Energy Budget Estimates of Fluxes over a Pine Forest', Quart. J. Roy. Meteorol. Soc. 101, $93-$ 105 . 